\title{
Analysis of development of carbonation and surface wear of the concrete: a case study in Ship Lock 1 of the transposition system of Tucuruí dam
}

\author{
Thais Valadares Oliveira ${ }^{1} \cdot$ André Alessandro Nogueira $^{2}$
}

Received: 30 June 2016/ Accepted: 7 November 2016/Published online: 28 November 2016

(C) Springer International Publishing Switzerland 2016

\begin{abstract}
Concrete is a material normally exposed to deterioration mechanisms that can reduce its service life. Among them, a widespread pathology is the carbonation: a natural reaction in concrete structures that occur due to the absorption of carbon dioxide $\left(\mathrm{CO}_{2}\right)$ present in the atmosphere by this material. Moderate carbonation rates can be beneficial to concrete. However, it causes the neutralization of the cement alkalis, reducing the hydrogenionic potential of this material. This study object was the Ship Lock 1, component of the Transposition System of Tucuruí Dam, which concrete has on average 33 years. Being a hydraulic structure, the concrete is inevitably exposed to alternating floods and droughts, obtaining, as product, the wear of its surface and the exposure of aggregates. Therefore, the surface wear, an abrasive effect of the water flow, is also a common deterioration mechanism of the concrete, especially in case that it is placed in the hydraulic surface of a dam. To this work concerns the analysis of the aforementioned processes, carbonation and surface wear of the concrete, as well as their interrelationship. Eleven samples of the vestments of the Ship Lock 1 were extracted in three pre-established horizontal bands, one above the maximum level of the water: reference for the present research. The depth of carbonation and surface wear were recorded. It was observed that the carbonation depth in the reference cores was larger, however, its surface wear was almost
\end{abstract}

Thais Valadares Oliveira

thaisvaladares.94@gmail.com

André Alessandro Nogueira

andre.nogueira@eletronorte.gov.br

1 Federal University of Pará, Tucuruí, Pará, Brazil

2 Eletrobras Eletronorte, Tucuruí, Pará, Brazil null. Moreover, those extracted in the bands stated below the maximum water level showed opposite results.

Keywords Carbonation - Concrete surface wear - Ship lock · Tucuruí dam · Transposition system · Pathology

\section{Introduction}

Concrete is a material widely used in civil construction, especially due to its low cost, excellent water resistance and flexibility of formats. However, as any other material, it is subjected to deterioration methods that can affect its service life. When a structure reaches the service life, it is unsafe to use it and extremely costly try to recover it. For this it is interesting to study and know the durability of this construction material. It can be known as a durable concrete that one which can keep its form, quality and the initial use ability in the environment for which it was designed [1]. Two deterioration mechanisms compound the bases of this work, carbonation and surface wear of the concrete, especially in dams, as will be described.

\subsection{Carbonation and surface wear}

Carbonation is defined as a physical-chemical process that progresses slowly in the interior of the concrete structures by penetration of carbon dioxide $\left(\mathrm{CO}_{2}\right)$ from the outer surface to the inside. It occurs naturally, depending only on the concentration of this gas in the atmosphere and on the humidity variation in the analyzed site. The progress of carbonation is directly linked to the easiness that the $\mathrm{CO}_{2}$ meets to diffuse itself through the concrete cover layer at a time. The $\mathrm{CO}_{2}$ penetration is regulated by the transport mechanisms and occurs by diffusion of gases through the 
pores and cracks. Thus, the pore structure and configuration of cracks, as well as the humidity present in the voids are determinant factors for $\mathrm{CO}_{2}$ to enter into the cement matrix [2].

$\mathrm{CO}_{2}$ is able to combine with the calcium hydroxide $\left(\mathrm{Ca}(\mathrm{OH})_{2}\right)$ present in the cement paste, among other products involved in the hydration process, resulting in compounds such as calcium carbonate $\left(\mathrm{CaCO}_{3}\right)$. Basically, the reaction develops as shown in Eq. 1 [3].

$$
\mathrm{Ca}(\mathrm{OH})_{2}+\mathrm{CO}_{2} \rightarrow \mathrm{CaCO}_{3}+\mathrm{H}_{2} \mathrm{O}
$$

The surface of the concrete layer when carbonated have increased their mechanical strength and reduced permeability due to the low solubility of the $\mathrm{CaCO}_{3}$ in water. However, in waters with high rates of $\mathrm{CO}_{2}$, there is formation of carbonic acid $\left(\mathrm{H}_{2} \mathrm{CO}_{3}\right)$, product of the association between water $\left(\mathrm{H}_{2} \mathrm{O}\right)$ and dissolved carbon dioxide $\left(\mathrm{CO}_{2}\right)$ (Eq. 2), which gradually melts carbonate layer, generating bicarbonate soluble [the calcium bicarbonate $\mathrm{Ca}\left(\mathrm{HCO}_{3}\right)_{2}$-for example], as described by Eq. 3. This process is called diffusion of calcium carbonate $\left(\mathrm{CaCO}_{3}-\right.$ insoluble) due to the attack of carbonic acid $\left(\mathrm{H}_{2} \mathrm{CO}_{3}\right)$ [4].

$\mathrm{H}_{2} \mathrm{O}+\mathrm{CO}_{2} \rightarrow \mathrm{H}_{2} \mathrm{CO}_{3}$

$\mathrm{CaCO}_{3}+\mathrm{H}_{2} \mathrm{CO}_{3} \rightarrow \mathrm{Ca}\left(\mathrm{HCO}_{3}\right)_{2}$

The presence of carbonic acid promotes a decrease in the hydrogenionic potential of the system, which becomes unable to maintain it high, due to the $\mathrm{H}+$ ions present, the $\mathrm{C}-\mathrm{S}-\mathrm{H}$ and even the anhydrous components $\left(\mathrm{C}_{3} \mathrm{~S}\right.$ or $\mathrm{C}_{2} \mathrm{~S}$ phases) remaining in the cement paste that dissociate in the form of amorphous silica. As a result, the concrete begins to behave as a highly porous and brittle material. Thus, high levels of carbonation can result in loss of structural integrity for the material [4].

As the water surface is in motion, dissolved bicarbonate is removed, opening the way for the reaction to continue replaying, leaving exposed the products that is not cementitious, shaped like silicon, aluminum and iron hydroxide gels, with inclusions of small aggregates. Equation 4 illustrates the process of repetition, when calcium hydroxide is attacked again by carbonic acid. Equation 5, in turn, shows this same compound being attacked by the calcium bicarbonate formed as described above in Eq. 2.

$$
\begin{aligned}
& 2 \mathrm{H}_{2} \mathrm{CO}_{3}+\mathrm{Ca}(\mathrm{OH})_{2} \rightarrow \mathrm{Ca}\left(\mathrm{HCO}_{3}\right)_{2}+2 \mathrm{H}_{2} \mathrm{O} \\
& \mathrm{Ca}(\mathrm{HCO})_{2}+\mathrm{Ca}(\mathrm{OH})_{2} \rightarrow 2 \mathrm{CaCO}_{3}+2 \mathrm{H}_{2} \mathrm{O}
\end{aligned}
$$

Although the attacked layer can be very weak, still has a certain diffusion resistance which slows degradation. However, when the weakened layer separates from the concrete (by erosion or fragmentation), the rate of degradation is increased. Hence, $\mathrm{CO}_{2}$ penetrates into the structure again, reacts with the calcium hydroxide and diffuses to the exterior, forming newly $\mathrm{CaCO}_{3}$ and letting the surface worn [4]. This process is gradual and continuous, causing substantial degradation to the studied block.

Surface wear of concrete occurs due to progressive losses of mass caused by erosion, abrasion or cavitation. When the wear is related to the abrasive effect of the impact of suspended solids carried by the water or other fluid, the term that is more used is erosion. Erosions are so common in hydraulic structures, as spillways, concrete pipes and canals coverings [1]. The more the flows are turbulent, greater the erosion [5].

The point is that the cement paste does not have high resistance to friction, especially if it is very porous or have low resistance. Therefore, repeated cycles of friction can easily shorten the useful life of the concrete, leading to a progressive surface wear $[1,5]$.

It is important to note that the structure under study, best described in the sequence, is a dam compounded by mass concrete. This type of concrete, in turn, resists their loadings due not only the concrete strength but also to their structural form and, in particular, its mass [6]. Therefore, such structures typically have low resistance, which associated with exposure to constant water flow naturally causes the surface wear of concrete over the years. Therefore, empirically measure the length of this wear and observe the linearity that it is developing along the upstream face of the analyzed structure is one of the aims of this work, amongst the measurement of the penetration depth of carbonation in this concrete.

\subsection{Study place description}

At $300 \mathrm{~km}$ in the straight south of Belém, state of Pará, Brazil, a dam was built on the Tocantins river, near the town of Tucuruí, and on this was implemented the Hydroelectric Power Plant of Tucuruí (HPP Tucuruí), as well as its Transposition System.

The HPP Tucuruí was built in order to generate electricity. On the other hand, the Transposition System of Tucuruí, compound by two locks and two canals, is a part of the projected Araguaia-Tocantins watercourse and has the function of allowing vessels to pass through the gap created by the dam. The HPP Tucuruí and Transposition System was built in two successive stages [7].

In the first stage, between 1975 and 1992, it was completed the interruption of the Tocantins River, built the spillway and the Powerhouse 1 , in which were installed twelve machines of $350 \mathrm{MW}$. The first generating unit went into operation in 1984. In the second stage, between 1998 and 2006, it was built the Powerhouse 2 and it was installed eleven generating units of $375 \mathrm{MW}$, totaling 8370 MW of capacity installed [7]. 
The Ship Lock 1 is located in the earth dam, which has interfered in the lake filling program, bringing the need to build its upstream head in the first construction stage, between 1982 and 1984. From there, the pace of work was declining until its complete standstill in 1989. The construction was resumed in 1999 and after repeated shutdowns and taken, was finally completed in 2010 [8]. The location of the Ship Lock 1 in relation to the complex of Tucuruí Dam can be observed in Fig. 1.

The total volume of concrete used in the two stages of the dam construction was approximately $8,000,000 \mathrm{~m}^{3}$ (eight million cubic meters), to which were added about $1,200,000 \mathrm{~m}^{3}$ (one million two hundred thousand cubic meters) applied in the structures that compound the Transposition System. The ship lock in the upstream part (Ship Lock 1) consists of a chamber with $210 \mathrm{~m}$ long and $33 \mathrm{~m}$ wide. It is intended to make the connection between the reservoir and the intermediate canal. It was consumed a volume of nearly $736,000 \mathrm{~m}^{3}$ (seven hundred thirty-six thousand cubic meters) of concrete, being applied $410.000,00 \mathrm{~m}^{3}$ (four hundred and ten thousand cubic meters) in the first stage of construction and the remainder in the second stage [8].

As object of this research, was chosen the upstream face of the Block 1-A1 of Ship Lock 1 (Fig. 2). The conditions considered for this decision were: (1) easy access to the local by authorized staff, because this is not inserted into the restricted area or high dangerousness-it does not belong to EPS (Electric Power System) and does not have electromechanical equipment related to energy generation; (2) the pioneer application of materials and constructive methods in this structure-it was the first permanent one in Brazil to receive the Roller Compacted Concrete (RCC), in 1982; (3) the operating time of it (31 years); and (4) its historical data (bank information). It is even important to mention that the study structure has not shown signs of bad effects on its safety and lifespan.

The Ship Lock 1 is located such that the axis of the earth dam passes through its upstream head. Then it is a part of

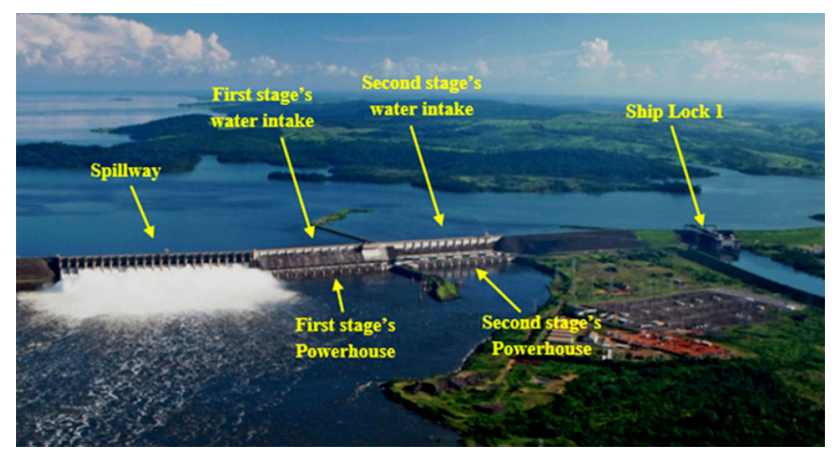

Fig. 1 Aerial view of the Tocantins river interruption, highlighting the main concrete structures that compose it

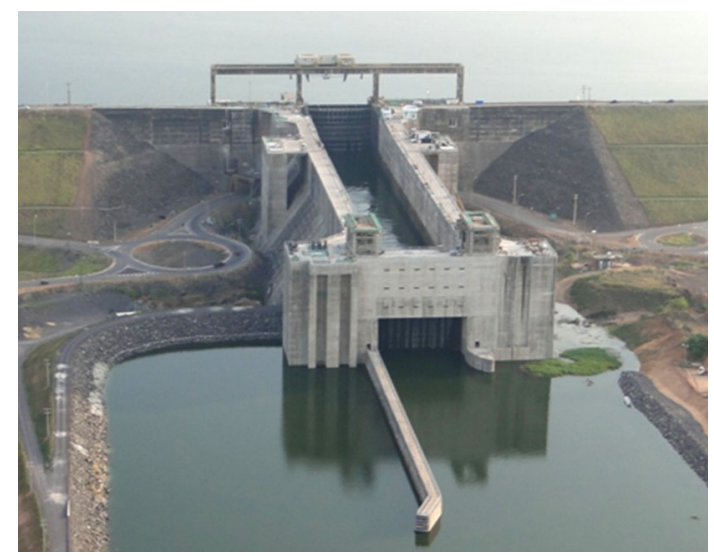

Fig. 2 Ship Lock 1 of the Tucuruí transposition system, in a downstream view

the gravity structure that compounds the dam and not reinforced. The connection between the Ship Lock 1 and the earth dam is made by connection walls (blocks 1-A1, 1-A2, 1-C1 and 1-C2).

One of the most important aspects of the technology of concrete is its behavior in front of the action of aggressive agents. Some chemicals are able to cause the deterioration of this material, which may impair the use of the structure. However, for this to occur, these substances must be in an electrolytic ionized state, i.e., dispersed in a liquid element that allows their cleavage [9].

Aggressive agents can utilize actions of physical or chemical nature: the physical nature are characterized by the occurrences of abrasion and erosion acting on the concrete structure; the chemical, in turn, are caused by the exchange of ions in an aqueous element, giving rise to soluble and insoluble compounds responsible for the generation of stresses able to disaggregate the concrete [9].

When the context is the quality of the concrete, there is usually an immediate concern about its resistance, often forgetting the indispensable factor, its durability. Essential especially in water structures, in which there is a spread use of concrete.

According to a concept present in the literature, "The durability of concrete is defined as its ability to resist the action of the weather, chemical attack, abrasion or any other deterioration process" [2]. Depending on climatic and environmental conditions, the concrete is exposed to the effects of a great number of aggressive agents and various destructive factors that can act in isolation, associating to each of them characteristic effects. The result of environmental interactions with the concrete microstructure is the change of its properties.

About the exposure to the environment, the surface of the upstream face of the body of a dam can be divided into three distinct areas, being them: 
- Submerged area-The largest part of the upstream face is almost always submerged, i.e., in constant contact with the water of the reservoir. This water may contain various aggressive components to concrete, such as waste from industries located on the banks of the reservoir; agrochemical plantations; organic matters from the decomposition of the vegetation present in the place before filling the reservoir; besides the very source of water [10];

- Above the maximum level zone-A portion of the surface of the upstream face is above the maximum level of the reservoir. Therefore, in constant contact with atmospheric gases and subject to degradation modes related to these, as is the case of the carbonation;

- Zone between the minimum and maximum operational-The third segment of the upstream face is submerged in a period of the year and exposed to the air in the other. This surface, when submerged, is in contact with water from the reservoir and its aggressive agents. Otherwise, when the level of the water gets lower, the surface becomes exposed to air, as well as to carbonation. However, the degradation mechanisms do not occur in isolation, or simply add up to each other, they work together, each one in its own time, so that this area is subject to a unique form of attack.

Because of its peculiar characteristic, the surface that is object of this study is contained in the zone between the minimum and maximum operational. In this case, as the upstream water-levels of the Ship Lock 1 are the same of the reservoir, the common maximum water-level is $74.00 \mathrm{~m}$ and the minimum, $58.00 \mathrm{~m}$-dimensions related to sea level. Therefore, this study was focused on the surface wear of the concrete located in the upstream face of 1-A1 Block of the Ship Lock 1, between water-levels $74.00 \mathrm{~m}$ and $58.00 \mathrm{~m}$. The location of this block in the whole structure is illustrated in Fig. 3.
Nowadays, 31 years after filling the reservoir, the concrete surface studied has rough appearance, with aggregates exposed. Thus, the layer of mortar that created a film between the aggregate and the mold at the time of concreting has been deteriorated, as shown in Fig. 4. Quantification of this wear and the investigation of its causes were studied and the results will be presented throughout this paper.

\section{Materials and methods}

For the execution of this work it was necessary to perform a destructive test in the surface of the upstream face of Ship Lock 1, in order to check the penetration depth of carbonation. The mentioned test consisted of the extraction of eleven cores from the concrete of this surface, with the aid of an extracting machine, EMIC brand, that has diamond crown and cup, with $100 \mathrm{~mm}$ of diameter, following the recommendations of ABNT NBR 7680-1 [11] as possible.

According to this standard, the ideal would be to extract cores that equalize or exceed three times the maximum diameter characteristic (MDC) of the aggregate of the analyzed concrete. In this case, MDC is equal to $76 \mathrm{~mm}$, which requires the extraction of at least $228 \mathrm{~mm}$ in diameter. This recommendation could not be followed due to the unavailability of an extractor with a drill of such dimensions.

With the extracted cores it was also possible to evaluate empirically the surface wear of the upstream face. From the comparison between those extracted above the maximum water-level (height $74.00 \mathrm{~m}$ ) —used as a reference in this work-which extraction band is called "top," and those below this, extracted in two different bands, called "middle" and "bottom". The points of extraction and their respective domain bands are shown in a schematic plan, present in Fig. 5.
Fig. 3 Plant without scale, showing the location of the 1-A1 Block [8]

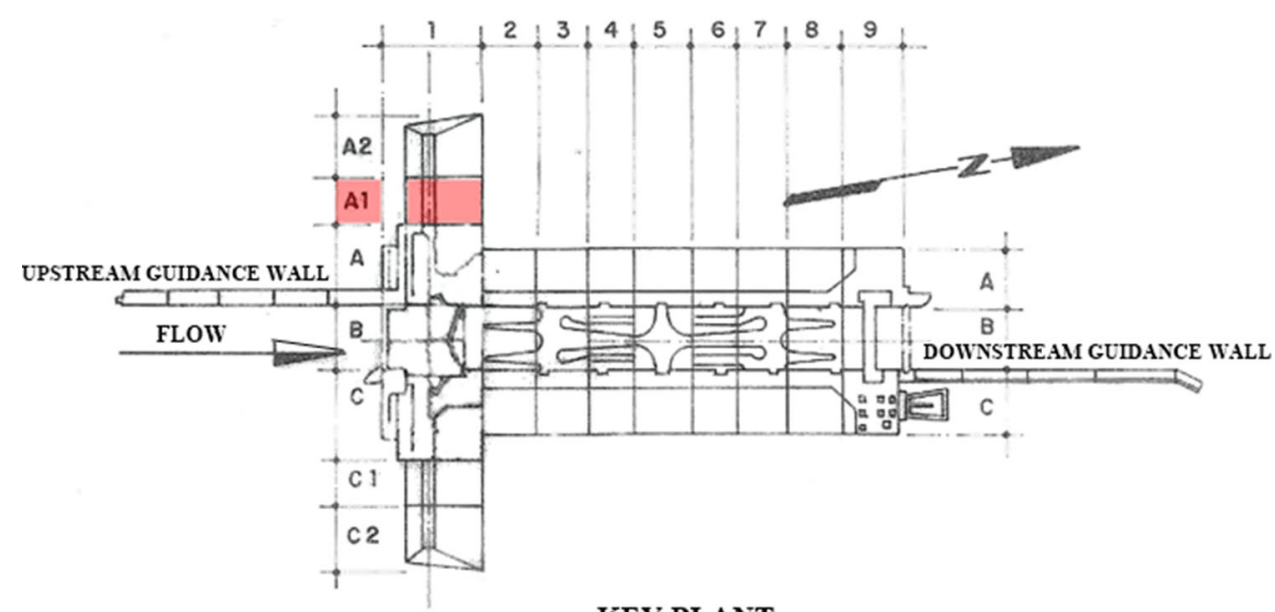

KEY PLANT

WITHOUT SCALE 


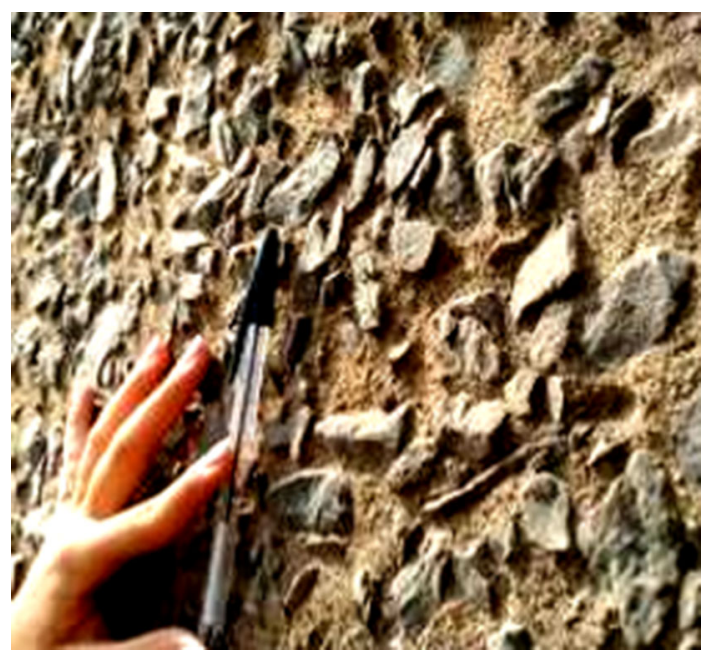

Fig. 4 Photo illustrating the surface wear of the upstream face of the Ship Lock 1

The samples were extracted in November 2015. For the implementation of this procedure, it was essential the help of a crane letting down and position in the upstream face of the ship lock the extractor near of a vertical position. The same was fixed on the concrete wall with the aid of steel plates and parabolts. The Fig. 6 illustrates the steps taken for the extraction of the cores, as described.

After extraction, each specimen received sprayed phenolphthalein solution, a commonly used acid-base indicator, prepared at the rate of $1 \%$ of phenolphthalein dissolved in $99 \%$ ethyl alcohol. This was applied in order to check the penetration depth of carbonation. As shown in Fig. 7, after applying the solution, a region where there is no color change indicates that has a hydrogenionic potential below 8.5. Therefore, noting the presence of carbonation. Meanwhile, another area of cores adopts pink coloration, demonstrating that it has a high hydrogenionic potential, basic character, as concrete typically presents with hydrogenionic potential around 12.5.

To quantify the penetration depth, counted with the aid of a caliper, Mitutoyo brand, Model CD-8' CS-B. The distance from the outer end of the test piece to the boundary line between the pink region and that has retained its original color-not carbonated and carbonated, respectively-was measured considering four equidistant points marked on the specimen base, as can be seen in Fig. 8 .

As to surface wear, its length was measured empirically, also making use of caliper and four equidistant points for the measurement of the distance between the top of the most exposed aggregate and mortared basis, using as reference the cores extracted above maximum water-level (A5, A-6 and A-7), adopted as little worn or not. Figure 9 illustrates the procedures adopted for the measurement of surface wear of the extracted specimens.

\section{Results and discussion}

The values obtained for the penetration depth of carbonation of the cores extracted from the concrete analyzed are shown in Table 1.

As noted by the analysis of the Table 1, in all samples, without exception, appears the carbonate, although in different proportions. This shows how much carbonation is a normal reaction to concrete structures, especially for those of advanced age, as the one studied (the upstream face of the Ship Lock 1 was concreted 33 years ago).

There is a clear difference between the results observed for the reference cores (top) and those from the bands "middle" and "bottom". The extracted cores of depth band "top" showed the highest values for carbonation, fact which can be justified by the greater exposure of this region, throughout the year, to atmospheric air, being more
Fig. 5 Schematic view showing the points of cores extraction in 1-A1 Block, in the Ship Lock 1

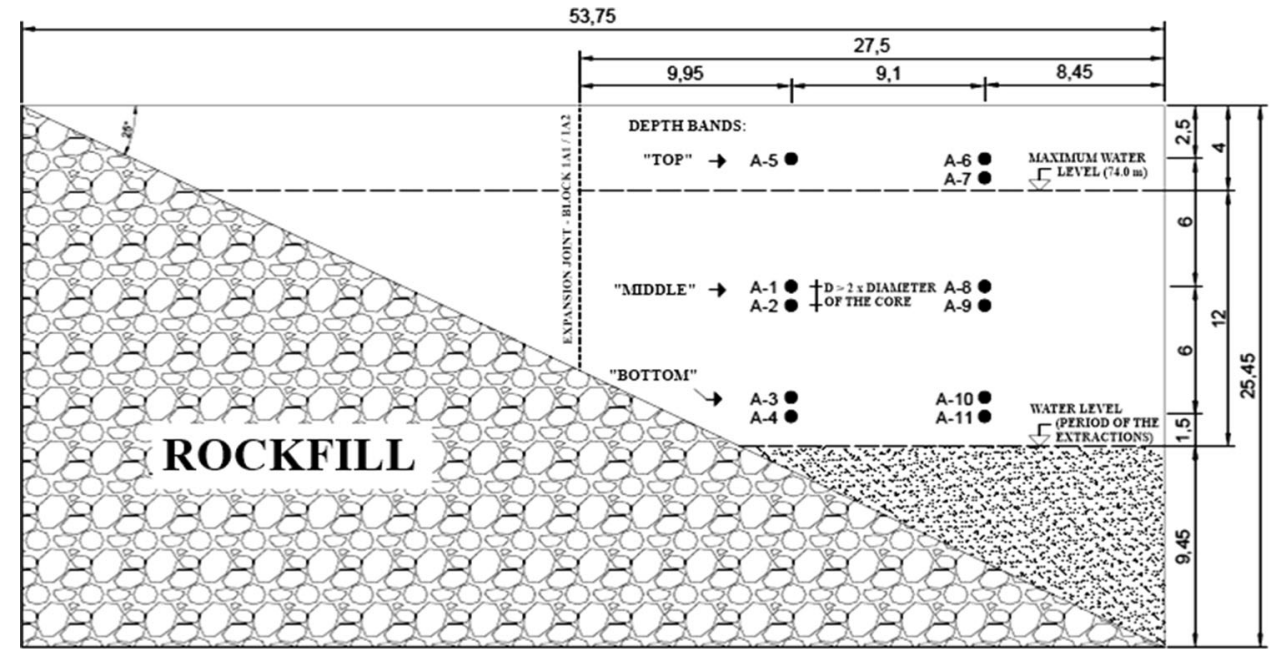


Fig. 6 a Cage supported by the crane during the positioning and manipulation of the extractor; b core extraction in the upstream face of the Ship Lock 1 , highlighting the situation of the extractor

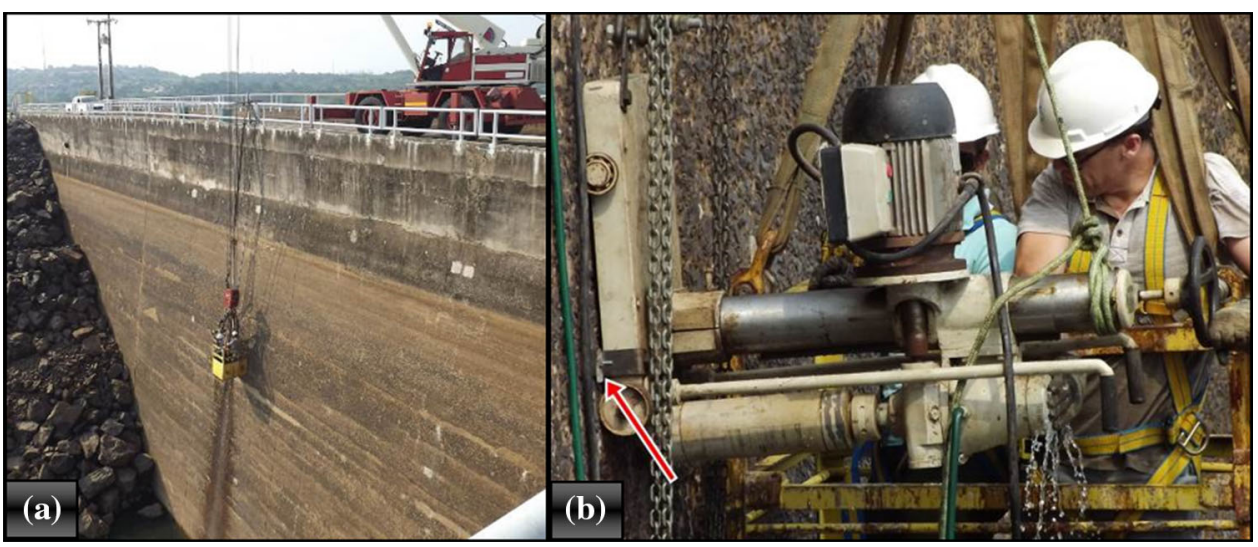

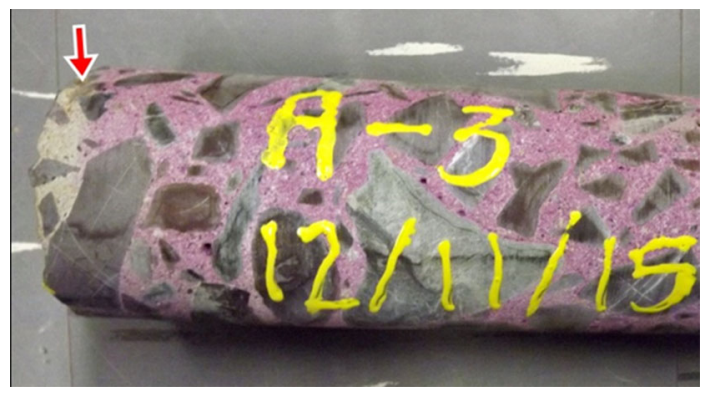

Fig. 7 How the core presented after being subjected to the phenolphthalein solution. The arrow indicates the carbonated region, which has retained its original color subjected to absorption of gases, like $\mathrm{CO}_{2}$, that causes the reaction.

On the other hand, the results of the bands "middle" and "bottom" showed lowers carbonation values, not exceeding half of the obtained for the reference band. Both of them follow basically the same proportion. That occurs because a great part of the year they are submerged, without contact with atmospheric $\mathrm{CO}_{2}$, being submitted to no more than that $\mathrm{CO}_{2}$ dissolved in water. The depth band "bottom" achieved results slightly lower than the band "middle", which is justified by the period in which the extractions were performed shortly after exposure to
Fig. 8 Procedure for measurement of penetration depth of carbonation, being: a the marking of points equidistant for carrying out readings; b measurement with the aid of the caliper
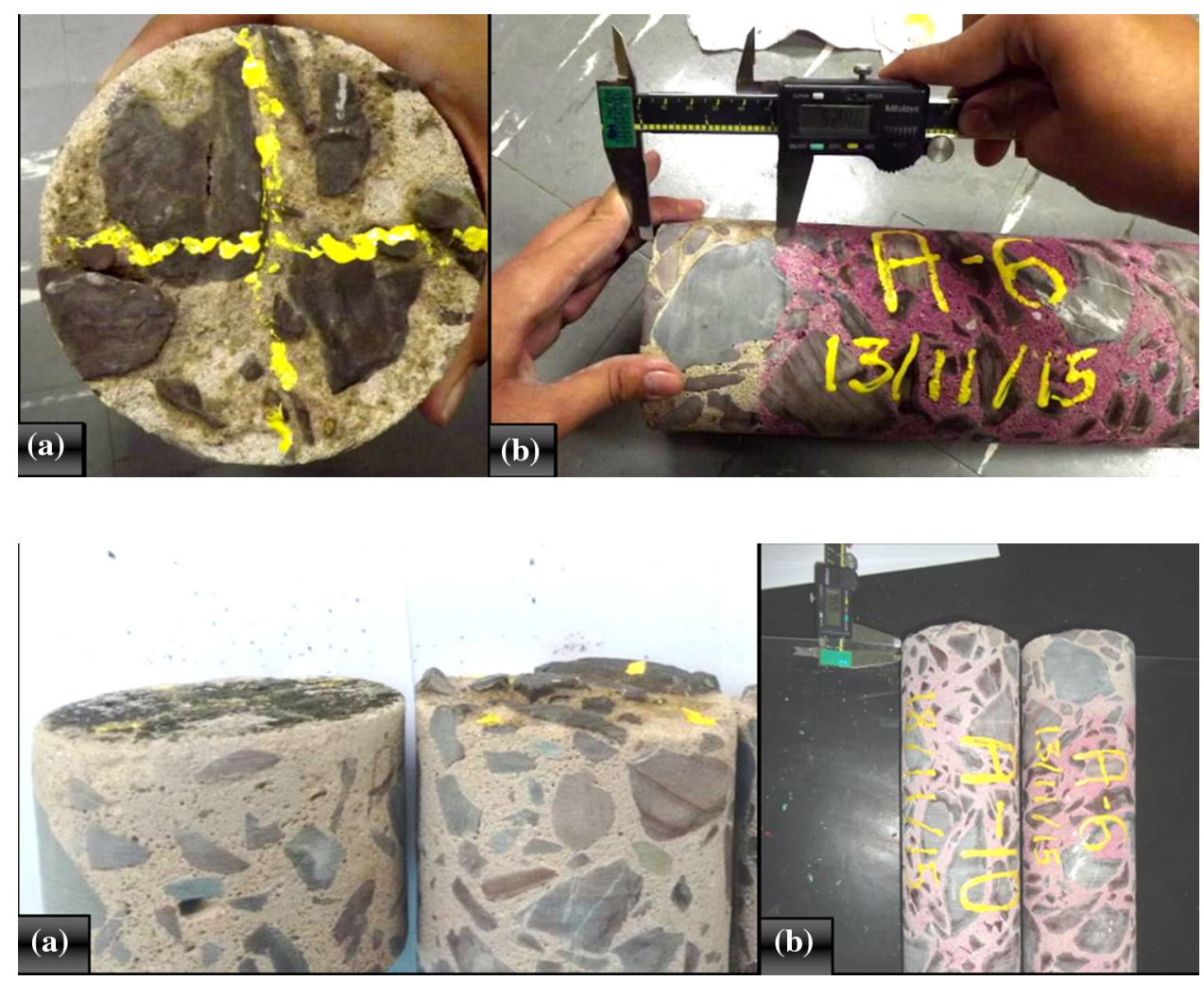

Fig. 9 a Positioning the specimens, being clear the difference between the surface of the reference core, in the left, and the examined for wear, at the right; $\mathbf{b}$ measuring the extent worn, with the help of caliper and a metal strip serving as a bridge between the reference sample and the analyzed one 
Table 1 Results for the penetration depth of carbonation

\begin{tabular}{lllrrrrr}
\hline Sample & Extraction date & Depth band & \multicolumn{6}{l}{ Penetration depth of carbonation $(\mathrm{mm})$} \\
\cline { 5 - 8 } & & & Point 1 & Point 2 & Point 3 & Point 4 & Average \\
\hline A-1 & $11 / 12 / 2015$ & Middle & 14.58 & 14.52 & 12.10 & 24.05 & 16.31 \\
A-2 & $11 / 12 / 2015$ & Middle & 26.74 & 37.45 & 10.85 & 30.96 & 26.50 \\
A-3 & $11 / 12 / 2015$ & Bottom & 11.43 & 13.48 & 11.23 & 13.89 & 12.51 \\
A-4 & $11 / 13 / 2015$ & Bottom & 19.85 & 17.99 & 29.09 & 25.83 & 23.19 \\
A-5 & $11 / 13 / 2015$ & Top & 102.59 & 106.12 & 105.31 & 105.31 & 104.83 \\
A-6 & $11 / 13 / 2015$ & Top & 52.40 & 49.55 & 52.85 & 47.98 & 50.70 \\
A-7 & $11 / 13 / 2015$ & Top & 55.44 & 57.50 & 50.21 & 52.89 & 54.01 \\
A-8 & $11 / 16 / 2015$ & Middle & 26.57 & 39.52 & 25.12 & 9.51 & 25.18 \\
A-9 & $11 / 16 / 2015$ & Middle & 22.28 & 25.79 & 11.24 & 24.70 & 21.00 \\
A-10 & $11 / 18 / 2015$ & Bottom & 18.40 & 10.96 & 10.24 & 10.35 & 12.49 \\
A-11 & $11 / 18 / 2015$ & Bottom & 16.73 & 13.43 & 14.23 & 18.38 & 15.69 \\
\hline
\end{tabular}

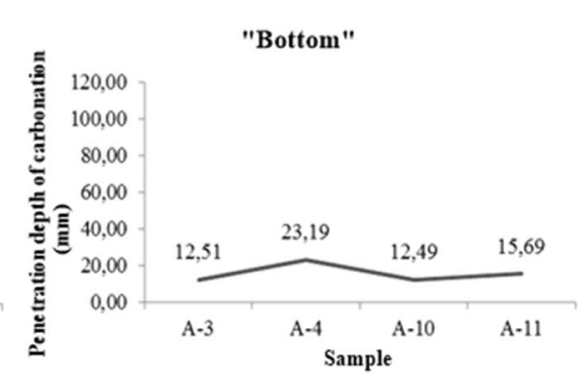

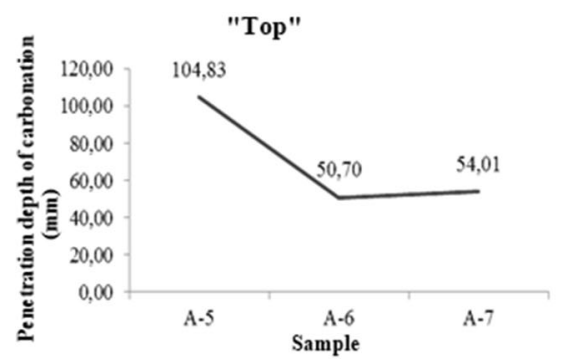

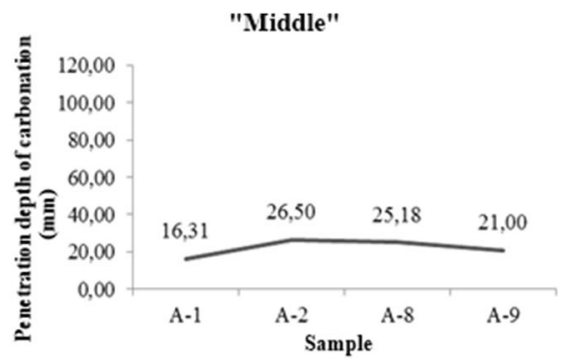

Fig. 10 Illustrating the depth of carbonation in the bands "top", "middle" and "bottom", respectively

atmospheric air, another track when it was already exposed for some time.

In addition to the points mentioned above, one should also consider the concrete saturation condition of the bands "middle" and "bottom". The $\mathrm{CO}_{2}$ transport within the concrete occurs by diffusion, therefore, pores very saturated interfere in the passage of the gas and consequently in the development of the carbonation. In opposition, pores partially filled with water make the entry easier, as occurs in the depth band "top".

Another thing that could be considered to justify the different penetration depths of carbonation between the bands is the concrete resistance and, consequently, its porosity. If there were distinct resistances in these bands, that could be also a reason to the different results. However, in the projects of the study structure all the upstream face, that has two meters of extend up until the center of mass concrete, was executed with the same concrete, projected to reach $15 \mathrm{MPa}$ in 28 days. So, at this time, this possibility is not considered applicable.

As mentioned in the previous chapter, cores used were not respecting all of the standard recommendations. However, this does not significantly interposed in the results of this test, since the focus of study is the analysis of carbonation depth in concrete that covers the upstream face, not checking the compressive strength of the cores, as is this standard object. Therefore, the diameter of $100 \mathrm{~mm}$ was sufficient.

In an illustrative purpose, Fig. 10 shows three graphs, one for each analyzed band, demonstrating its penetration depth values of carbonation. As can be noticed through it, the sample A-5 proved to be an exception, with values much higher than the others in the same band. This event can be justified by any cracking or failure of site concreting, which eventually enlarge the air exposure of this region deterioration mechanisms such as carbonation.

Table 2 below shows the results obtained for superficial wear of the witness. Since the A-5, A-6 and A-7 samples were used as a reference in its measurement, its wear was considered by approximation equal to zero.

Observing the average of the values obtained for the surface wear, they do not follow a rule, randomly varying according to the point of extraction. Results are coming, ranging from the most $(7.65 \mathrm{~mm})$ to the lowest $(4.25 \mathrm{~mm})$ in only $3.4 \mathrm{~mm}$.

The fact that all the samples taken below the maximum water-level having some surface wear highlights the homogeneity of this deterioration process throughout the region comprised within the band between the minimum and maximum operational. As described above, wear is 
Table 2 Results for the surface wear

\begin{tabular}{llllllll}
\hline Sample & Extraction date & Depth band & \multicolumn{5}{l}{ Surface wear $(\mathrm{mm})$} \\
\cline { 5 - 8 } & & & Point 1 & Point 2 & Point 3 & Point 4 & Average \\
\hline A-1 & $11 / 12 / 2015$ & Middle & 5.93 & 5.48 & 8.12 & 4.39 & 5.98 \\
A-2 & $11 / 12 / 2015$ & Middle & 10.68 & 8.41 & 2.87 & 7.59 & 7.39 \\
A-3 & $11 / 12 / 2015$ & Bottom & 3.17 & 4.46 & 7.72 & 7.14 & 5.62 \\
A-4 & $11 / 13 / 2015$ & Bottom & 3.85 & 6.13 & 9.63 & 5.89 & 6.38 \\
A-5 & $11 / 13 / 2015$ & Top & - & - & - & - & - \\
A-6 & $11 / 13 / 2015$ & Top & - & - & - & - & - \\
A-7 & $11 / 13 / 2015$ & Top & - & - & - & - & - \\
A-8 & $11 / 16 / 2015$ & Middle & 10.73 & 5.61 & 6.67 & 7.60 & 7.65 \\
A-9 & $11 / 16 / 2015$ & Middle & 5.45 & 4.50 & 5.07 & 4.29 & 4.83 \\
A-10 & $11 / 18 / 2015$ & Bottom & 8.56 & 7.91 & 5.29 & 6.52 & 7.07 \\
A-11 & $11 / 18 / 2015$ & Bottom & 2.62 & 2.68 & 5.85 & 5.84 & 4.25 \\
\hline
\end{tabular}

induced from the formation of carbonic acid $\left(\mathrm{H}_{2} \mathrm{CO}_{3}\right)$ in the water reservoir, due to the presence of $\mathrm{CO}_{2}$. This compound dissolves carbonated layer every full cycle and drought, causing surface erosion of the cement paste and leaving exposed the peak of aggregates.

Although it is a mechanism of deterioration of the material, if one considers the age of the concrete (33 years) and the period to which it is exposed to variations in the waterlevel of the reservoir (31 years), a wear of only $10.73 \mathrm{~mm}$ (highest value, regardless of medium) is very small compared to the length of the structure. By adopting an average width of $20 \mathrm{~m}$ between the upstream and the downstream face of 1-A1 Block there is a wear which is $0.05 \%$ of this dimension, not featuring any risk to its structural integrity.

\section{Conclusion}

After the completion of this study, it was found that the development of carbonation in all regions analyzed, both the area above the maximum operating water-level and the area between the minimum and maximum operational are exposed to this deterioration mechanism. The first zone cited showed the higher values for penetration depth of carbonation, indicating its greater exposure to atmospheric air.

In the analysis of the surface wear, the area above the maximum operating, called for the band of extraction "top" was the most entirety part superficially, considered reference to samples from other bands. These other, distributed in the zone between the minimum and maximum operational, all showed surface wear and, consequently, aggregates exposure. This is not an alarming fact, because it is a very small erosion in comparison to the extension of the structure, on the order of $0.05 \%$ of its width.

Thus, even found the occurrence of the two deterioration mechanisms discussed validating the execution of the study, the structure is not deemed compromised. On the contrary, considering its 33 years in operation, the concrete upstream face of the Ship Lock 1 is exceptionally intact, being unnecessary to make interventions in the short term.

Acknowledgements To Eletrobras Eletronorte, for supporting research, allowing full access to structure of the Ship Lock 1 and providing the equipment necessary for the development of the study, including from the crane, extractor, caliper and many other materials and documents necessary for the assessment of the problem.

\section{References}

1. Mehta PK, Monteiro PJM (2008) Concreto: microestrutura, propriedades e materiais, 3rd edn. IBRACON, São Paulo

2. Papadakis VG, Vayenas CG, Fardis MN (1991) Fundamental modeling and experimental investigation of concrete carbonation. ACI Mater J 88:363-373

3. Ribeiro DV (2013) Corrosão em estruturas de concreto armado: teoria, controle e métodos de análise. Elsevier Group, Rio de Janeiro

4. Ekström T (2001) Leaching of concrete: experiments and modelling. Laund University, Suécia

5. Galvão JCA, Portella KF, Kormann ACM (2012) Chapter 2: abrasive effects observed in concrete hydraulic surfaces of dams and application of repair materials. In: abrasion resistance of materials. InTech; 2012

6. American Concrete Institute-ACI (1980) ACI manual of concrete practice-Part 1. Detroit: ACI, 1980

7. Herweg C, Fernandes, FE, Gama HR, Bandeira, OM, Lacerda SS (2004) Avanços técnicos aplicados na construção das estruturas de concreto da Barragem de Tucuruí. In: Conferência Internacional Conjunta ACI—IBRACON. São Paulo: IBRACON/ACI; 2004

8. Centrais Elétricas do Norte do Brasil S (1988) A Eletronorte. Usina Hidrelétrica Tucuruí: Memória do Empreendimento. 2nd vol. Brasília: ELETRONORTE; 1988

9. Furnas laboratory staff (1997) Concretos massa, estrutural, projetado e compactado com rolo: ensaios e propriedade. Pini, São Paulo

10. Santi MRA (2008) Metodologia para avaliação da perda de massa em barragem de Concreto Compactado com Rolo (CCR). Curitiba: UFPR, Dissertation

11. Associação Brasileira de Normas Técnicas-ABNT (2015) NBR 7680-1: Concreto-Extração, preparo, ensaio e análise de testemunhos de estruturas de concreto-parte 1: Resistência à compressão axial. Rio de Janeiro: ABNT 